\title{
Prevalence and Factors Associated with Raised Intraocular Pressure among Hypertensive Patients-A Hospital-Based Study, Uganda
}

\author{
Mwanja Pius $^{1 *}$, Ayebare Pauline1,2, Erima Denis ${ }^{1,2}$, Zalwango Charity ${ }^{1,3}$, Ampaire Anne1, \\ Ateenyi Agaba C1,4,5 \\ ${ }^{1}$ Makerere University, College of Health Sciences, Kampala, Uganda \\ ${ }^{2}$ Mbarara University of Science and Technology, Mbarara, Uganda \\ ${ }^{3}$ Ryazan State Medical University, Ryazan, Russia \\ ${ }^{4}$ London School of Hygiene and Tropical Medicine, London, England \\ ${ }^{5}$ Karolinska Institiute, Solna, Sweden \\ Email: *mwanjapius@gmail.com, ayebline16@gmail.com, deni-remas@hotmail.com, charityzally@yahoo.com, \\ annemusika@gmail.com, ateeniagabac@gmail.com
}

How to cite this paper: Pius, M., Pauline, A., Denis, E., Charity, Z., Anne, A., and Agaba C, A. (2020) Prevalence and Factors Associated with Raised Intraocular Pressure among Hypertensive Patients-A Hospital-Based Study, Uganda. Open Journal of Ophthalmology, 10, 351-363.

https://doi.org/10.4236/ojoph.2020.104038

Received: October 6, 2020

Accepted: November 27, 2020

Published: November 30, 2020

Copyright $\odot 2020$ by author(s) and Scientific Research Publishing Inc. This work is licensed under the Creative Commons Attribution International License (CC BY 4.0).

http://creativecommons.org/licenses/by/4.0/ (c) (i) Open Access

\begin{abstract}
Background: Raised intraocular pressure (IOP) is a major risk factor for glaucoma. Hypertensive patients are at a risk of developing and progression of Open Angle Glaucoma (OAG) which is a major cause of blindness in the world. The aim of this study was to determine the prevalence of raised IOP and associated factors among hypertensive patients attending the hypertension clinic at Mulago National Referral Hospital in Uganda. Materials and Methods: A cross-sectional study was conducted from December 2018 to March 2019. Our sample comprised hypertensive patients recruited after obtaining consent. Participants were sampled consecutively and underwent both a general medical and ocular examination. A questionnaire was used to collect data on socio-demographic characteristics, ocular and medical factors. Data were entered into the computer using the statistical data package of Epidata version 3.1 and exported to STATA version 14 for analysis. Results: Of the 405 hypertensive study participants, mean age was 57.1 years (range 25 to 90 years, $\mathrm{SD}=12.4$ years). The overall prevalence of raised intraocular pressure was $11.6 \%$ (95\% CI 8.8 - 15.1). The mean IOP among all participants was $15.2 \mathrm{mmHg}(\mathrm{SD}=4.3)$ with a range of $3-34 \mathrm{mmHg}$. The factors with a statistically significant association with raised intraocular pressure after multivariate analysis were a positive family history of Glaucoma (OR 57, CI 10.33 315.34, P < 0.001) and Eye trauma (OR 7.84, CI $1.02-60.02 \mathrm{P}=0.047)$. Conclusions: The prevalence of raised intraocular pressure among hypertensive patients attending the hypertension clinic in Mulago National Referral hospi-
\end{abstract}


tal, Uganda was found to be high.

\section{Keywords}

Prevalence, Associated Factors, Raised Intraocular Pressure, Systemic Hypertension, Glaucoma, Mulago National Referral Hospital, Uganda

\section{Introduction}

Raised Intraocular pressure (IOP) is a major risk factor for glaucoma. Hypertensive patients are at a risk of developing and progression of Open Angle Glaucoma (OAG) which is a major cause of blindness [1].

Glaucoma refers to a group of diseases that have in common a characteristic optic neuropathy with associated visual function loss. Although elevated intraocular pressure (IOP) is one of the primary risk factors, its presence or absence does not have a role in the definition of the disease [2]. Of the major risk factors for glaucoma development and progression, age and genetic predisposition have no interventional potential [3] leaving only IOP as the only parameter subject to treatment.

Glaucoma is the second leading cause of blindness after cataracts [4] [5] and hypertension is thought to increase the risk of development of glaucoma [6] [7]. In Africa, glaucoma accounts for $15 \%$ blindness and it is the region with the highest prevalence of blindness relative to other places in the world [4]. Also, Open Angle Glaucoma (OAG) is more prevalent among Africans than Europeans [8].

Systemic hypertension affects more than $25 \%$ of the adult population worldwide and it is predicted to affect more than 1.5 billion individuals by 2025 [9] [10]. One of the community surveys done in Uganda put the prevalence of hypertension at 7\% [11]. Also, numerous population-based studies have found a positive correlation between IOP and systemic blood pressure [12] [13]. However, even though raised IOP can easily be treated, its prevalence among hypertensive patients in Uganda is unknown. This is risky, because, owing to the asymptomatic nature of Open Angle Glaucoma, most of these patients will not know it until they have developed irreversible complications.

Therefore, the aim of this study was to investigate the prevalence of raised IOP and associated factors among hypertensive patients attending the hypertension clinic in Mulago National Referral Hospital (MNRH) in Uganda.

\section{Materials and Methods}

This was a hospital-based cross-sectional study, conducted over a period of four months in Mulago National Referral Hospital, Directorate of medicine, in the hypertension clinic that is run in the Medical Outpatient Department which operates in Kiruddu General Hospital. Ethical approval was obtained from the 
Makerere University School of Medicine Institutional Review Board. Using a modification of Leslie's Kish sample size estimation formula, a sample size of 405 patients was found to be adequate. Participants were sampled consecutively after being reviewed by the physician on duty and underwent both a general medical and ocular examination plus a questionnaire to collect data on socio-demographic characteristics.

\subsection{Inclusion Criteria}

- All hypertensive patients who attended the hypertension clinic in Kiruddu General Hospital during the study period (December 2018-March 2019) and voluntarily consented to participate in the study.

\subsection{Exclusion Criteria}

- Patients with known allergies to eye drops used in the study e.g. local anesthetic drops like tetracaine and mydriatic eye drops like tropicamide.

- Those with corneal irregularities that could affect the IOP readings e.g. in anterior segment pathology like corneal opacities and ulcers, collagen disorders like keratoconus, Endothelial-based corneal dystrophies (e.g., Fuchs), Previous corneal surgery involving Central cornea, Previous cornea trauma/injury, Previous refractive surgery, Corneal edema, Corneal astigmatism $(\geq 3.00 \mathrm{D})$, Contact lens wear with induced corneal edema.

- Patients who are too sick to endure the entire exercise of interviewing and the medical examination.

\subsection{Procedure}

On arrival at the hypertension clinic, all patients were consented for inclusion (written consent) into the study right after being seen by the physician on duty, interviewed with a questionnaire by a research assistant to capture socio-demographic data, medical and past ocular history followed by doing blood pressure measurement and a full eye examination by the Principal Investigator. To avoid recruiting a participant twice, an identification sticker was put in the file of the recruited study participant after consenting.

Blood pressure (B.P) was measured using a manual sphygmomanometer and when systolic blood pressure was $>130 \mathrm{~mm} \mathrm{Hg}$ or a diastolic blood pressure $>$ $80 \mathrm{~mm} \mathrm{Hg}$ the blood pressure was considered to be raised or high. The B.P reading taken from the clinic served to give information about the level of control of a patient's hypertension and not to be used as a means of diagnosis of the hypertensive status as all the study participants recruited already had a physician's diagnosis of hypertension.

Visual acuity (V/A) was measured using a Snellen chart at $6 \mathrm{~m}$ or illiterate $\mathrm{E}$ chart; those with V/A worse than $6 / 18$ were reassessed with a pinhole. Vision better or equal to $6 / 18$ in distance vision was considered normal and that worse than $6 / 18$ was considered impaired vision. Near acuity test was performed with a 
hand held Jaeger eye chart.

The Intraocular Pressure (IOP) was assessed with the i-care tonometer after applying tetracaine $\mathrm{Hcl} 0.1 \%$. Three consecutive readings were taken and the average recorded as the measured IOP in $\mathrm{mmHg}$. The IOP measurements were taken from 9 am to 12 noon by the principal investigator to avoid diurnal variation. IOP levels between 10 and $21 \mathrm{mmHg}$ were considered normal. Values higher than $21 \mathrm{mmHg}$ were considered raised IOP and below $10 \mathrm{mmHg}$ were considered as ocular hypotension.

Dilation of the pupil was done using tropicamide eye drops to allow a dilated fundus assessment using a portable bio-microscopic slit-lamp with a 90D or 78D lens.

\subsection{Statistical Analysis}

Bivariate logistic regression analysis was used to establish the relationship between the dependent variable (IOP) and each independent variable. All variables with P-values below 0.2 were considered in multivariate analysis. At multivariate analysis, logistic regression was used to find the relationship between the dependent variable and the predictors. Predictors with P-value less than 0.05 were considered to be statistically significant and associated with raised IOP. Interaction and then confounding was assessed for. Odds ratios were reported with their confidence intervals. The goodness of fit of the final model was assessed using the Hosmer and Lemeshow statistics. Predictors with P-value less than 0.05 were considered to be significantly associated with raised IOP.

\section{Results}

A total of 405 hypertensive participants were recruited into this study. Most of the participants were female $73.2 \%(\mathrm{n}=298)$ with $32(10.7 \%)$ females having raised IOP as compared to $15(14 \%)$ males. Also, a vast majority of the participants were of Bantu origin 96.54\% $(n=391)$. A larger proportion of the participants denied having smoked $97.78 \%(\mathrm{n}=396)$. Also, most of the participants were not involved in physical exercise $60.5 \%(\mathrm{n}=245)$ as seen in Table 1 . As shown in Table 1, most of the hypertensive patients had a duration of $1-10$ years of being hypertensive $60.99 \%(n=247)$ with a large proportion being on antihypertensive medication $93.83 \%(\mathrm{n}=380)$ and many of the participants also had diabetes mellitus as a co-morbidity $47.16 \%(\mathrm{n}=191)$. Among the study participants, $92.59 \%(\mathrm{n}=382)$ had no history of previous eye surgery. In addition, of those that had eye surgery, $34.78 \%(\mathrm{n}=8)$ had cataract surgery, $17.39 \%(\mathrm{n}=$ 4) had pterygium surgery while $47.83 \%(n=11)$ had other ocular surgeries. Among the 297 study participants found to have refractive errors, presbyopia $(97.31 \% \mathrm{n}=289)$ was predominant.

The mean age of the participants was $57.1(\mathrm{SD} \pm 12.4)$ ranging from 25 to 90 years with largest age group being the one of $51-60$ years as seen in Figure 1 below. 
Table 1. A table showing the socio-demographic and clinical characteristics and among hypertensive patients attending the hypertension clinic in Mulago National Referral Hospital.

\begin{tabular}{|c|c|c|}
\hline Variable & Frequency $(N=405)$ & Percentage \\
\hline \multicolumn{3}{|l|}{ Sex } \\
\hline Male & 107 & 26.42 \\
\hline Female & 298 & 73.58 \\
\hline \multicolumn{3}{|l|}{ Ethnicity } \\
\hline Bantu & 391 & 96.54 \\
\hline Nilotics & 8 & 1.98 \\
\hline Nilo-hamites & 4 & 0.99 \\
\hline Others & 2 & 0.49 \\
\hline \multicolumn{3}{|l|}{ Smoking } \\
\hline Does not smoke & 396 & 97.78 \\
\hline Smokes & 9 & 2.22 \\
\hline \multicolumn{3}{|l|}{ Physical exercise } \\
\hline Doesn't do physical exercise & 245 & 60.5 \\
\hline Does physical exercise & 160 & 39.5 \\
\hline \multicolumn{3}{|l|}{ Duration of hypertensive state } \\
\hline Less than one year & 65 & 16.05 \\
\hline One to 10 years & 247 & 60.99 \\
\hline Between 10 and 20 years & 54 & 13.33 \\
\hline More than 20 years & 39 & 9.63 \\
\hline \multicolumn{3}{|l|}{ Hypertension treatment } \\
\hline Patient on drugs & 380 & 93.83 \\
\hline Patient not on drugs & 25 & 6.17 \\
\hline \multicolumn{3}{|l|}{ History of Diabetes } \\
\hline Yes & 191 & 47.16 \\
\hline No & 175 & 43.21 \\
\hline Not sure & 39 & 9.63 \\
\hline \multicolumn{3}{|l|}{ Eye surgery } \\
\hline No & 382 & 92.59 \\
\hline Yes & 23 & 5.68 \\
\hline \multicolumn{3}{|l|}{ Type of surgery $(n=23)$} \\
\hline Cataract surgery & 8 & 34.78 \\
\hline Pterygium & 4 & 17.39 \\
\hline Others & 11 & 47.83 \\
\hline \multicolumn{3}{|l|}{ Refractive error } \\
\hline No & 108 & 26.67 \\
\hline Yes & 297 & 73.33 \\
\hline \multicolumn{3}{|l|}{ Type of refractive error $(n=297)$} \\
\hline Presbyopia & 289 & 97.31 \\
\hline Myopia & 8 & 2.69 \\
\hline
\end{tabular}


Among the subgroup of hypertensive participants taking anti-hypertensive medication, $43(11.3 \%)$ had raised IOP while of those not on drugs with raised IOP numbered $4(16 \%)$ as reflected in Figure 2 below.

Raised IOP was more frequent among patients with refractive errors, cataract and Glaucoma as compared to pterygium and allergic conjunctivitis. However, patients with bacterial conjunctivitis and dry eye had no raised IOP as shown in Figure 3 below.

When the factors associated with raised IOP were analyzed using both bivariate and multivariate models, only the association between raised IOP and: a positive family history of Glaucoma and Eye trauma remained statistically significant (p-value less than 0.20 ) after multivariate analysis as shown in Table 2 below.

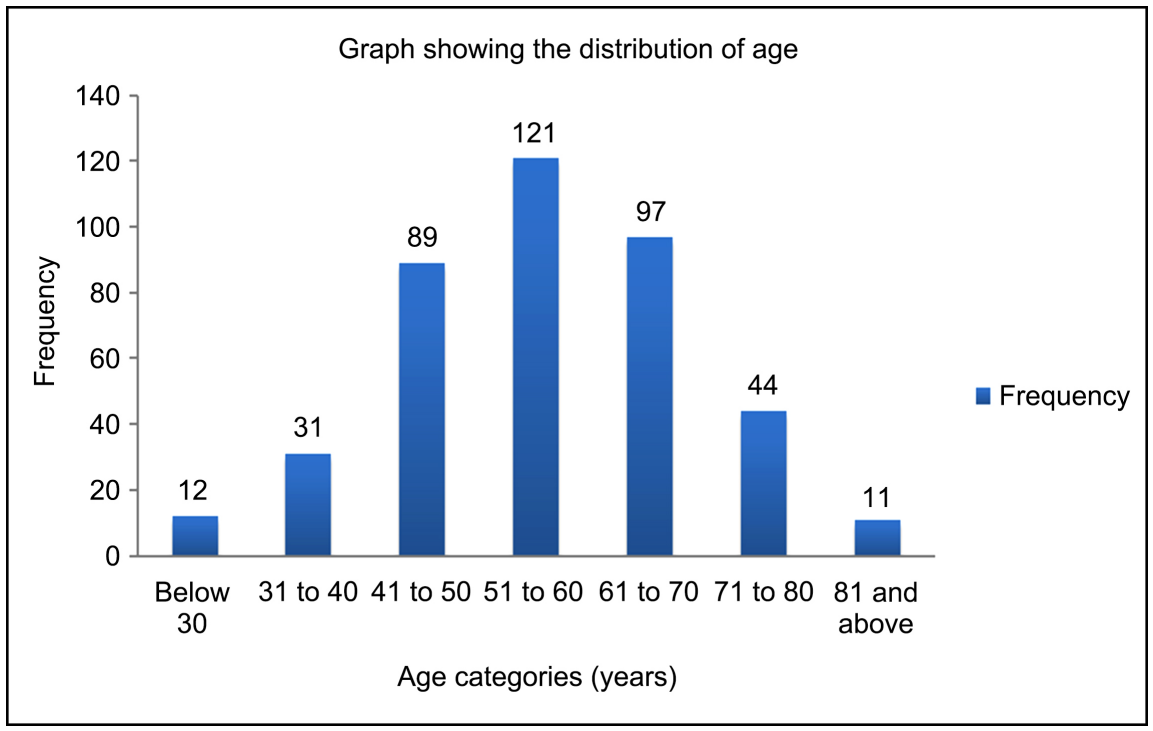

Figure 1. Showing the age distribution of participants.

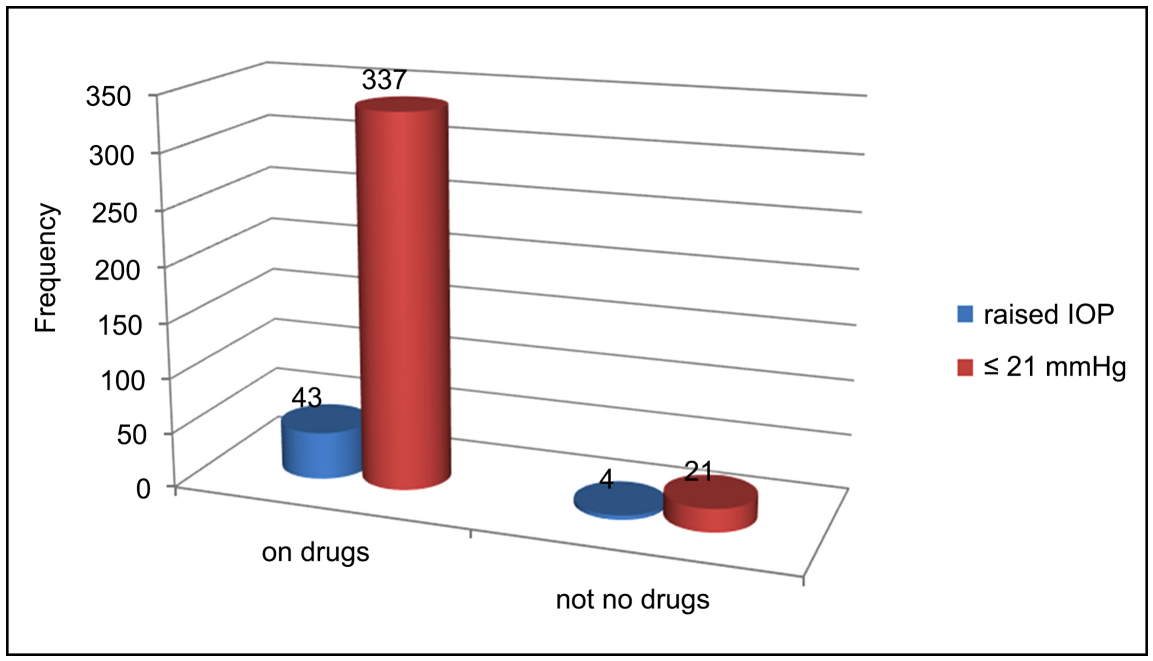

Figure 2. Frequency of raised Intraocular pressure as compared between participants on anti-hypertensive medication and those not on medication. 
Table 2. A table of Multivariate analysis of factors associated with raised intraocular pressure among hypertensive patients attending the hypertension clinic in Mulago National Referral Hospital.

\begin{tabular}{ccccc}
\hline \multirow{2}{*}{ Variable } & Normal & Raised & \multicolumn{2}{c}{ Multivariate analysis } \\
\cline { 2 - 5 } & $\mathrm{n}(\%)$ & $\mathrm{n}(\%)$ & OR (95\% CI) & P value \\
\hline
\end{tabular}

\section{Smoking}

No

Known Glaucoma patient

$\begin{array}{cccc}\text { Yes } & 38(39.2) & 9(40.9) & 1 \\ \text { No } & 59(60.8) & 13(59.1) & 1.14(0.48-2.67)\end{array}$

\section{Eye Trauma}

No

\section{Eye Surgery}

No

Hypertension treatment

No

\section{Blood pressure}

Normal

\section{Cataract}

No

Glaucoma family history

$\begin{array}{lccc}\text { No } & 356(99.4) & 37(78.7) & 1 \\ \text { Yes } & 2(0.6) & 10(21.3) & 57(10.33-315.34)\end{array}$

\section{Refractive error}

\begin{tabular}{lcccc} 
No & $151(42.2)$ & $34(72.3)$ & 1 & 0.076 \\
Yes & $207(57.8)$ & $13(27.7)$ & $0.50(0.23-1.06)$ & \\
\hline
\end{tabular}

$\begin{array}{ccc}355(99.2) & 45(95.7) & 1 \\ 3(0.8) & 2(4.3) & 7.84(1.02-60.02)\end{array}$

0.047

$\begin{array}{cccc}340(95.0) & 42(89.4) & 1 & \\ 18(5.0) & 5(10.6) & 0.98(0.23-4.25) & 0.982\end{array}$

$\begin{array}{ccc}21(5.9) & 4(8.5) & 1 \\ 337(94.1) & 43(91.5) & 0.56(0.17-1.84)\end{array}$

0.340

$255(71.2) \quad 36(76.6) \quad 1.41(0.62-3.24)$

$\begin{array}{ccc}328(91.6) & 39(83.0) & 1 \\ 30(8.4) & 8(17.0) & 2.00(0.68-5.89)\end{array}$

0.207

0.000 


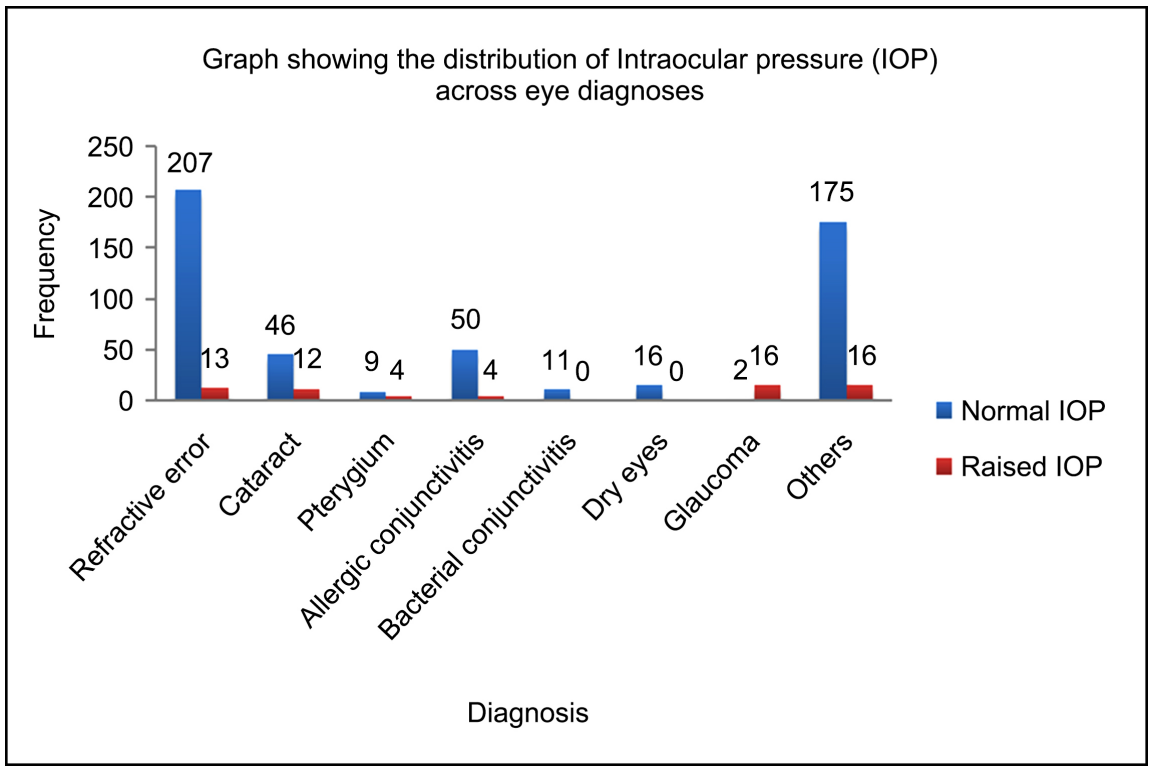

Figure 3. Showing common ocular diagnoses as compared with IOP frequency among hypertensive patients attending the hypertension clinic in Mulago National Referral Hospital.

The factors with a statistically significant association with raised intraocular pressure after multivariate analysis were a positive family history of Glaucoma (OR 57, CI 10.33 - 315.34, $\mathrm{P}<0.001$ ) with participants 57 times more likely to have raised IOP and Eye trauma (OR 7.84, CI $1.02-60.02 \mathrm{P}=0.047)$ with participants approximately 8 times more likely to have raised IOP.

\section{Discussion}

In this study, the overall prevalence of raised intraocular pressure among hypertensive patients attending the hypertension clinic in Mulago National Referral Hospital was $11.6 \%$. The high prevalence from this study may not however only be attributed to the hypertensive status of the participants in this study as all of the study recruits were of the African heritage and the majority were of advanced age (mean age $=57.1, \mathrm{SD} \pm 12.4$ ) -both being known risk factors for Open Angle Glaucoma. This was comparable to the prevalence of 10\%; (95\% CI: $6.2 \%-15.7 \%$ ) found in a study done in South Africa to determine the prevalence of a diagnosis of raised intraocular pressure in general practice [14]. It however differs from that in a Hospital-based cross-sectional observational study done in Al-Khobar, Saudi Arabia where the prevalence of raised intraocular pressure was 8.7\% among 458 participants using Perkins hand-held applanation tonometry [15].

Also, most of the participants were female $73.2 \%(n=298)$ and this could partly be explained by the poor health-seeking behavior of the male gender in Uganda [16] where the most influencing factors were found to be conformity to masculinity coupled with high cost of health care.

Considering $\mathrm{P}$ value of $<0.05$ as statistically significant at $95 \%$ confidence in- 
terval, there was no statistically significant association between these factors; age, sex, smoking, incisional eye surgery, blood pressure measurement, BMI, exercise history, refractive errors, being a known glaucoma patient, diabetes mellitus, hyperlipidemia, renal and hepatic disease, use of anti-hypertensive medication and duration of use of anti-hypertensive medication with raised intraocular pressure. This study however found a statistically significant relationship between the factors eye trauma and a positive family history of glaucoma with raised intraocular pressure.

In this study, there was a statistically significant relationship between patients having a positive family history of Glaucoma and raised intraocular pressure (OR 57, CI 10.33 - 315.34, P < 0.001) with them being 57 times more likely to have raised IOP. The above phenomenon is further supported by a study which showed that a positive family history of glaucoma is a risk factor for increased IOP [17].

We also found a statistically significant relationship (OR 7.84 CI1.02 - 60.02 P $=0.047$ ) between eye trauma and raised intraocular pressure. Literature has shown that ocular injury can lead to secondary glaucoma in the traumatized eye. The mechanism of pressure elevation is often multifactorial. One of the main mechanisms is tearing of the anterior chamber angle and iris root, causing posterior angle synechiae and angle recession formation, leading to a decrease in the outflow of the aqueous humor and thus an increase in IOP. The IOP may increase even years after the injury. This was comparable to a retrospective study [18] that found that traumatic IOP elevation was common in visually salvageable open globe injury even after 2 years post globe repair (prevalence $=23.3 \%$ ).

Our study found a high prevalence of raised intraocular pressure among hypertensive patients attending the hypertension clinic in Mulago National Referral Hospital and this provides a useful insight into the magnitude of risk for glaucoma among this vulnerable population.

\section{Study Limitations}

Due to logistical challenges, intraocular pressure in this study was measured using i-care rebound tonometry instead of the gold standard method of Goldmann applanation tonometry.

\section{Recommendations}

Routine screening and monitoring of Intraocular pressure in hypertensive patients for early detection of raised IOP and early intervention to prevent Glaucoma-associated blindness.

\section{Acknowledgements}

The authors owe their gratitude to the entire department of Ophthalmology at Mulago National Referral Hospital for their unfailing support, knowledge and guidance. This accomplishment would not have been possible without them. 


\section{Financial Support}

No financial support was received for this submission.

\section{Conflicts of Interest}

None of the authors has conflicts of interest with this submission.

\section{References}

[1] Langman, J.S.M., Lancashire, J.R., Cheng, K.K. and Stewart, M.P. (2005) Systemic Hypertension and Glaucoma: Mechanisms in Common and Co-Occurrence. British Journal of Ophthalmology, 89, 960-963. https://doi.org/10.1136/bjo.2004.053397

[2] Foster, P.J., Buhrmann, R., Quigley, H.A. and Johnson, G.J. (2002) The Definition and Classification of Glaucoma in Prevalence Surveys. British Journal of Ophthalmology, 86, 238.

[3] Kwon, Y.H., Fingert, J.H., Kuehn, M.H. and Alward, W.L. (2009) Primary Open-Angle Glaucoma. The New England Journal of Medicine, 360, 1113-1124. https://doi.org/10.1056/NEJMra0804630

[4] Resnikoff, S., Pascolini, D., Etya'ale, D., Kocur, I., Pararajasegaram, R., Pokharel, G.P. and Mariotti, S.P. (2004) Global Data on Visual Impairment in the Year 2002. Bulletin of the World Health Organization, 82, 844-851.

[5] Pascolini, D. and Mariotti, S.P. (2012) Global Estimates of Visual Impairment: 2010. The British Journal of Ophthalmology, 96, 614-618. https://doi.org/10.1136/bjophthalmol-2011-300539

[6] Rouhiainen, H.J. and Teräsvirta, M.E. (1990) Hemodynamic Variables in Progressive and Nonprogressive Low Tension Glaucoma. Acta Ophthalmologica (Copenhagen), 68, 34-36.

[7] Leighton, D.A. and Phillips, C.I. (1972) Systemic Blood Pressure in Open Angle Glaucoma, Low Tension Glaucoma and the Normal Eye. The British Journal of Ophthalmology, 56, 447-453. https://doi.org/10.1136/bjo.56.6.447

[8] Park, S., Nam, Y.P., Sung, K.K. and Kook, M.S. (2009) Structural and Functional Relationships in Glaucoma Using Standard Automated Perimetery and Humphrey Matrix. Korean Journal of Ophthalmology, 23, 176-182. https://doi.org/10.3341/kjo.2009.23.3.176

[9] Kearney, P.M., Whelton, M., Reynolds, K., Muntner, P., Whelton, P.K. and He, J. (2005) Global Burden of Hypertension: Analysis of Worldwide Data. Lancet, 365, 217-223. https://doi.org/10.1016/S0140-6736(05)17741-1

[10] Hedner, T., Narkiewicz, K. and Kjeldsen, S.E. (2005) Hypertension Control-A Global Challenge. Blood Pressure, 14, 4-5. https://doi.org/10.1080/08037050510034266

[11] Guwatudde, D., Mutungi, G., Wesonga, R., Kajjura, R., Kasule, H., Muwonge, J., et al. (2015) The Epidemiology of Hypertension in Uganda: Findings from the National Non-Communicable Diseases Risk Factor Survey. PLoS ONE, 10, e0138991. https://doi.org/10.1371/journal.pone.0138991

[12] Leske, M.C. and Podgor, M.J. (1983) Intraocular Pressure, Cardiovascular Risk Variables, and Visual Field Defects. American Journal of Epidemiology, 118, 280-287. https://doi.org/10.1093/oxfordjournals.aje.a113634

[13] Klein, B.E. and Klein, R. (1981) Intraocular Pressure and Cardiovascular Variables. Archives of Ophthalmology, 99, 837-839. 
https://doi.org/10.1001/archopht.1981.03930010837009

[14] Van Niekerk, M., Van Rooyen, F.C., Joubert, G. and Hiemstra, L.A. (2006) The Prevalence of the Diagnosis of Increased Intra-Ocular Pressure in a General Practice. South African Family Practice, 48, 16.

https://doi.org/10.1080/20786204.2006.10873351

[15] Yassin, S.A. and Al-Tamimi, E.R. (2016) Age, Gender and Refractive Error Association with Intraocular Pressure in Healthy Saudi Participants: A Cross-Sectional Study. Saudi Journal of Ophthalmology, 30, 44-48.

https://doi.org/10.1016/j.sjopt.2015.11.007

[16] Lubega, G.N., Musinguzi, B., Omiel, P. and Tumuhe, J.L. (2015) Determinants of Health Seeking Behaviour among Men in Luwero District. Journal of Education Research and Behavioral Sciences, 4, 37-54.

[17] Uhm, K.B. and Shin, D.H. (1992) Positive Family History of Glaucoma Is a Risk Factor for Increased IOP Rather than Glaucomatous Optic Nerve Damage (POAG vs $\mathrm{OH}$ vs Normal Control). Korean Journal of Ophthalmology, 6, 100-104. https://doi.org/10.3341/kjo.1992.6.2.100

[18] Bojikian, K.D., Stein, A.L., Slabaugh, M.A. and Chen, P.P. (2015) Incidence and Risk Factors for Traumatic Intraocular Pressure Elevation and Traumatic Glaucoma after Open-Globe Injury. Eye, 29, 1579-1584. https://doi.org/10.1038/eye.2015.173 


\section{Appendix}

\section{A1. Data Collecting Tool}

Questionnaire of the study to determine the prevalence and factors associated with raised IOP and associated factors among hypertensive patients attending the hypertension clinic in Mulago National Referral Hospital.

Date Participant Identity No

Phone. Time.

\section{A2. History}

\section{A2.1. Socio-Demographic Data}
1) Sex
a) Male
b) Female

2) Age (completed years)

3) Tribe

4) Do you smoke cigarettes?

a) Yes

b) No

5) If yes, how many per day?

6) Do you do physical exercises?
a) Yes
b) No

7) If yes, which type?
a) Rope skipping
b) Swimming
c) Walking
d) Others (specify)

8) Frequency
a) Daily
b) Once a week
c) Twice a week
d) Thrice a week
e) Others (specify)

9) Average duration
a) Less than $30 \mathrm{~min}$
b) More than $30 \mathrm{~min}$

\section{A2.2. Eye History}
1) Do you have glaucoma?
a) Yes
b) No
c) Not sure

2) If yes, for how long have you known this

3) Is there a first degree relative with glaucoma? a) Yes $\begin{array}{lll}\text { b) No } & \text { c) Unsure }\end{array}$
4) History of cataract?
$\begin{array}{lll}\text { a) Yes } & \text { b) No }\end{array}$
5) History of refractive errors?
$\begin{array}{lll}\text { a) Yes } & \text { b) No }\end{array}$

6) If yes, which type?

7) History of eye trauma?

a) Yes b) No

8) History of surgical operation on eye?

a) Yes

b) No

c) Not sure

\section{A2.3. Medical History}
1) Do you have diabetes?
a) Yes
b) No
c) Not sure
2) Are you a known patient of heart disease? a) Yes
b) No 
3) If yes, which type (specify)?

4) Are you a known patient of liver disease?

$\begin{array}{ll}\text { a) Yes } & \text { b) } \mathrm{No}\end{array}$

5) If yes, which type (specify)?

6) Are you a known patient of kidney disease? a) Yes b) No

7) If yes, which type (specify)?

8) Are you a known patient of hyperlipidemia? a) Yes b) No

9) How long have you known that you are a hypertensive patient?
10) Are you on anti-hypertensive drugs?
a) Yes
b) No

11) If yes, which anti-hypertensive drugs are you on?

12) Duration:

13) Is there a history of defaulting on treatment and for how long?

14) Are you taking a corticosteroid?

a) Yes

b) No

15) If yes, which type (specify)?

16) Which route of administration (specify)?

17) For how long?

a) Less than 8 weeks

b) More than 8 weeks

\section{A3. Examination}

General Examination

Blood pressure ( $\mathrm{mmHg}$ )

Weight $(\mathrm{kg})$

Height (metres)

BMI

\section{Ocular Examination}

RIGHT EYE

LEFT EYE

Visual acuity (best corrected):

IOP: (mmHg)

Eyelids:

Conjunctiva

Cornea:

Anterior chamber:

Pupil:

Lens

Vitreous

Fundus: Disc

CDR

Macular

Peripheral retina:

Visual field (by confrontation)

Diagnosis:

Treatment: 